\title{
Chapter 5 \\ Climate Policy in Power Sector: Feed-in Tariff and Carbon Pricing
}

\author{
Yukihide Kurakawa
}

\begin{abstract}
The purpose of this chapter is to investigate the effects of some mainstream policy schemes in the power sector on the reduction of $\mathrm{CO}_{2}$ emissions. The first part of this chapter is the analysis on the effects of promoting generation (fuel) efficiency of fossil-fuel power generation, specifically assuming more efficient coalfired power plants that recently indicates increased presence in the Japanese power sector. Improvement in generation efficiency of fossil-fuel power plants is expected to reduce emissions of carbon dioxide mainly from a technological aspect. However, overall effects on carbon reduction in the whole industry would be ambiguous since it also depends on market structure. The increased efficiency in generation leads to an improvement in cost conditions of fossil-fuel power producers relative to their rivals. It enables them to expand their generation and market share. Analyzing the Cournot oligopoly model, it is shown that an improvement in fossil-fuel power generations produces two effects: the 'saving effect' and the 'rebound effect'. The total $\mathrm{CO}_{2}$ emission in the whole industry decrease if the former effect exceeds the other, and vice versa. In addition, it is indicated that a rise in the generation efficiency would increase a difficulty of implementing carbon tax. In the second part of this chapter, I study the combination of feed-in tariff and carbon tax; that would be worthy to investigate since they could possibly complement each other. FIT policy could be financed by the revenue of carbon tax, and a reduction in electricity supply by the carbon tax would be lessen by supporting renewable power generations under FIT. It is demonstrated that FIT had the combined effects: it fosters a competitive environment in addition to indirectly reduces $\mathrm{CO}_{2}$ emissions. The result indicates that the combination of these policies would produce potential welfare gains.
\end{abstract}

Keywords Generation (fuel) efficiency $\cdot$ Carbon tax $\cdot$ Feed-in tariff

\footnotetext{
Y. Kurakawa (凶)

Faculty of Economics, Kanazawa Seiryo University, 10-1 Ushi, Gosho-machi, Kanazawa, Ishikawa 920-8620, Japan

e-mail: kurakawa@ seiryo-u.ac.jp
}

T. H. Arimura and S. Matsumoto (eds.), Carbon Pricing in Japan, 


\section{Introduction}

\subsection{Background}

There are several turning points in the history of energy use. The invention of the Watt steam engine in the late eighteenth century driven the industrial revolution and led to a rapid growth in coal consumption. In the 1950s, successive discovery of oilfields in the Middle East and Africa brought about a shift from coal to oil as a major source of energy. Since then, economies in various countries had become more dependent on political and diplomatic situations of oil-producing nations. That poses potential risks associated with social and economic stability in various countries. The oil crises in the 1970s revealed the risk from energy use highly dependent on petroleum. That triggered a promotion of usage of alternative energy sources like natural gas and nuclear power as well as energy conservation policies in order to improve energy security. After the adoption of the United Nations Framework Convention on Climate Change (UNFCCC) in 1992, there has been a growing recognition of the global warming as a problem of global issue.

Nuclear power has occupied an important position not only as a major energy source but also as a low-carbon power source which plays a substantial role in reducing $\mathrm{CO}_{2}$ emissions as well as increasing energy security; uranium is distributed in countries with relatively stable political conditions and is able to release greater thermal energy with smaller amount than fossil fuels. On the other hand, the issue of securing a final disposal site for radioactive waste still remains unsettled. In addition, the costs for safety measures at nuclear power generation facilities has increased after the Fukushima Daiichi Nuclear Power Station accident in 2011, that has been increasing the difficulty of constructing new nuclear power plants nowadays.

In that context, promoting renewable energies has become an increasingly more important policy issue to tackle the problems of global warming and energy security in recent years. Accordingly, many countries have implemented support schemes to promote renewable power generations.

Feed-in tariff (FIT) is the mainstream policy scheme that is particularly effective in promoting renewable energies. Despite its effectiveness, it usually causes an operational difficulty of making delicate adjustment in quantities of renewable energies, since it is a kind of price regulation under which the government sets a price for renewable electricity leaving the quantities to the market; practically it is difficult for the government to grasp precise cost conditions of the renewable power producers. The main purpose of the FIT policy is to reduce renewable power generation costs to the competitive level by encouraging technological developments and producing efficiency gains from mass production (e.g., the learning effect). Indeed, many countries adopting FIT policy are aiming at transition to a support schemes that are more relevant to the market mechanism such as feed-in premiums (FIP) and bidding systems when the FIT policy successfully creates competitive cost conditions of renewable power generations. 
Additionally, there exist the financing problem with FIT which tend to receive public attentions since it would be partly passed on to consumers. On the other hand, it is noteworthy to say that supporting renewable energy generations would partially overlaps with fostering the competitive environment in the industry that is formerly characterized by high market concentrations and entry barriers, because the new entrants would be heavily subsidized by the FIT; eventually it would has the effect of decreasing the consumer price. The analysis of the later part of this chapter primarily focuses on this aspect of FIT in addition to its effects as a climate policy in the power sector.

\subsection{Outline}

The major instruments for carbon reduction in the power sector typically involves the environmental and regulatory policy schemes which can be classified as the following categories,

1. Improving energy efficiencies

2. Carbon pricing

3. Promoting non-fossil fuel energy sources.

The first category covers approaches to both the supply-side and demand-side efficiencies: efficiencies of producing and using energies, respectively. The second category contains carbon tax and cap and trade schemes. The third category mainly represented by support schemes for promoting renewable energy sources, e.g., feedin tariff (FIT), feed-in premium (FIP), and renewable portfolio standard (RPS). As for Japanese power sector, FIT has been implemented since 2012, and partly combined with the bidding system for large-scale photovoltaics from 2017.

In the first part of this chapter, I will be examining a linear model to investigate the effects of generation efficiency and carbon tax. I will also be focusing on the interrelationship between these factors. In the next part, I will analyze a model with quadratic cost functions to examine the effects of feed-in tariff, as well as combination with feed-in tariff and carbon tax.

\section{Generation Efficiency and Carbon Tax}

I will begin the analysis by considering a linear model in which the cost functions and the demand function of the market are all linear to examine the overall effect of generation efficiency of the fossil-fuel power plants (specifically suppose coal fired power plants here) on carbon reduction. Following previous works such as Tamás et al. (2010) and Böhringer and Rosendahl (2010), I consider a liberalized ${ }^{1}$ Cournot

\footnotetext{
${ }^{1}$ Armstrong et al. (1994) states a distinction between "deregulation" and "liberalization"; the former would represent the removal of regulations such as price control as well as the removal of restrictions
} 
oligopoly market which is consisted of $n$ identical fossil-fuel power producers and $m$ identical renewable power producers. ${ }^{2}$ The inverse demand function is assumed to be as follows,

$$
P(Q):=A-B Q
$$

where $P=P(Q)$ is the consumer price and $Q$ is the total electricity supplied by both fossil-fuel and renewable power producers.

The profit of each fossil-fuel power producer is given by,

$$
\pi_{F}^{i}:=\left(P-c_{F}-a\right) y_{i}-k_{F}, i=1, \cdots, n
$$

where $y_{i}$ is the amount of electricity supply, $c_{F}$ is the constant marginal cost, and $k_{F}$ is the fixed cost. Let $a$ denote the access charge for each unit of electricity which is paid to the network operator in order to access the transmission network. The marginal cost of fossil-fuel power generation $c_{F}$ is composed of fuel cost and carbon tax:

$$
c_{F}:=p_{F} \theta+t(\eta \theta),
$$

where $\theta(\mathrm{kg} / \mathrm{kWh})$ represents the amount of fuel needed to produce $1 \mathrm{kWh}$ of electricity, it is equivalent to the generation efficiency of power plants, ${ }^{3} p_{F}$ is the fuel price (yen $/ \mathrm{kg}$ ), and $t$ is the carbon price (equivalent to a tax for each unit of emissions of carbon dioxide). Let $\eta\left(\mathrm{kg}-\mathrm{CO}_{2} / \mathrm{kg}\right)$ denote the carbon intensity of fuel; that represents the amount of $\mathrm{CO}_{2}$ emissions generated from burning $1 \mathrm{~kg}$ of fossil-fuel. ${ }^{4}$ Substituting Eq. (2), Eq. (1) can be rewritten as follows,

$$
\pi_{F}^{i}:=\left(P-p_{F} \theta-a\right) y_{i}-t\left(\eta \theta y_{i}\right)-k_{F}, i=1, \cdots, n .
$$

where $\eta \theta y_{i}$ is the emission of the $i$-th fossil-fuel power producer, which is represented as $e_{i}=\eta \theta y_{i}$. Accordingly, the total emission in the electric power sector is,

$$
E:=\eta \theta \sum_{i} y_{i}
$$

Similarly, the profit of the renewable producer $j$ is written as,

$$
\pi_{R}^{j}:=\left(P-c_{R}-a\right) x_{j}-k_{R}, j=1, \cdots, m,
$$

on competition. For clarity, they use "liberalization" to mean the removal of restrictions on competition. Following them, I use "liberalized market" here to represent the competitive environment under environmental regulations such as FIT.

${ }^{2}$ As Tamás et al. (2010) pointed out, market concentration in the electricity markets often high despite liberalization.

${ }^{3}$ Note that lower (higher) $\theta$ corresponds to higher (lower) generation efficiency.

${ }^{4}$ The amount of emission by producer $i$ is given by $\eta \theta y_{i}\left(\mathrm{~kg}-\mathrm{CO}_{2}\right)$. 
where $x_{j}$ is the amount of electricity supply, $c_{R}$ is the constant marginal cost, and $k_{R}$ is the fixed cost.

By solving the profit maximization problems, the first order conditions for fossilfuel and renewable power producers are obtained as follows,

$$
\begin{gathered}
\frac{\partial \pi_{F}^{i}}{\partial y_{i}}=\left\{A-B Q-p_{F} \theta-a\right\}-B y_{i}-t(\eta \theta)=0 \\
\frac{\partial \pi_{R}^{j}}{\partial x_{j}}=\left\{A-B Q-c_{R}-a\right\}-B x_{j}=0
\end{gathered}
$$

Assuming the symmetry ( $y_{i}=y$ for all $i$, and $x_{j}=x$ for all $j$ ) in the equilibrium, the equilibrium outcomes can be obtained as follows,

$$
\begin{gathered}
y=\frac{A-(m+1)\left(p_{F} \theta+t \theta \eta\right)+m c_{N}-a}{(n+m+1) B}, \\
x=\frac{A-(n+1) c_{N}+n\left(p_{F} \theta+t \theta \eta\right)-a}{(n+m+1) B}, \\
Q=\frac{(n+m)(A-a)-n\left(p_{F} \theta+t \theta \eta\right)-m c_{N}}{(n+m+1) B} .
\end{gathered}
$$

In order to secure positive outputs of the fossil-fuel and renewable power producers, it is assumed in the following analysis that $A-(n+1) c_{N}-a>0$ and $\theta<\bar{\theta}$, where

$$
\bar{\theta}:=\frac{A+m c_{N}-a}{(m+1)\left(p_{F}+t \eta\right)} .
$$

\subsection{Generation Efficiency}

Contrary to the worldwide trend toward restrictions or 'divestment' on coal-related projects in recent years, the Japanese Ministry of Economy, Trade and Industry (METI), as well as former monopolists in the electric power industry are positive about promoting coal-fired power generations. They rather place emphasis on technological measures for carbon reductions, i.e., developing low emission technologies that would reduce emissions of carbon dioxide such as higher-efficient power plants, CCS (Carbon dioxide Capture and Storage) and CCU (Carbon dioxide Capture and Utilization).

Japanese electric power companies shut down nuclear power plants in May 2011 after Fukushima Daiichi Nuclear Power Station Accident. METI and the former 
monopolists in the power sector regard coal fired power generation as a good alternative to nuclear power. They have become more enthusiastic to promote coal fired power generation after the accident. In addition, the Japanese government aims to export high efficiency coal fired power plants to the developing countries.

Improvement in generation efficiency of fossil-fuel power plants is expected to reduce emissions of carbon dioxide mainly from a technological aspect; more efficient power plants are able to produce the same amount of electricity with less fuel input. Consequently, it enables cutting fuel consumption and carbon emissions maintaining the electricity output. However, overall effects on carbon reduction in the whole industry would be ambiguous since it also depends on market structure. The increased efficiency in generation leads to an improvement in cost conditions of fossil-fuel power producers relative to their rivals. It enables them to expand their generation and market share. It may cause a net increase in total $\mathrm{CO}_{2}$ emission in the industry. We need to take this factor related to the market structure into account when we consider to what extent does promoting more efficient power plants contribute to carbon reduction in the whole industry.

To examine the impact of changes in generation efficiency of fossil-fuel power plants, the derivatives of the equilibrium outcomes with respect to $\theta$ are calculated as follows,

$$
\begin{gathered}
\frac{d y}{d \theta}=-\frac{(m+1)\left(p_{F}+t \eta\right)}{(n+m+1) B}<0, \\
\frac{d x}{d \theta}=\frac{n\left(p_{F}+t \eta\right)}{(n+m+1) B}>0, \\
\frac{d Q}{d \theta}=\frac{-n\left(p_{F}+t \eta\right)}{(n+m+1) B}<0 .
\end{gathered}
$$

Note that $d y / d \theta<0$. This means that an improvement (reduction) in generation efficiency, which is equivalent to a decrease (increase) in $\theta$, leads to a lager (smaller) output of fossil-fuel power producers. A higher generation efficiency improves cost conditions of fossil-fuel generators. This gives them a competitive advantage relative to their rivals: renewable electricity producers. To sum up, improvement in generation efficiency leads to an increase in output of fossil-fuel power producers and reduces output of renewable power producers, and vise-versa. The total output rises with higher generation efficiency.

The effect on the overall $\mathrm{CO}_{2}$ emission is given by,

$$
\frac{d E}{d \theta}=n \eta\left(y+\theta \frac{d y}{d \theta}\right) .
$$

The first term in the bracket indicates the direct effect of fuel conservation. A higher generation efficiency (lower $\theta$ ) can cut carbon emissions due to fuel conservation. The second term indicates the indirect effect through the market in which the 
fossil-fuel power producers expand their production with improved cost conditions relative to their rivals. It causes the adverse effect through changing in the market equilibrium. ${ }^{5}$ Improvement in generation efficiency reduces total emission of the power sector if the direct effect outweighs the indirect effect, and vice versa. Note that a reduction in $\theta$ increases the former effect but decreases the latter. Substituting Eqs. (7) and (10) into Eq. (13) yields,

$$
\frac{d E}{d \theta}=n \eta\left(\frac{A-2 \theta(m+1)\left(p_{F}+t \eta\right)+m c_{N}-a}{(n+m+1) B}\right) .
$$

The sign of Eq. (14) depends only on the sign of numerator of fraction in the bracket. We can obtain a threshold, ${ }^{6}$

$$
\hat{\theta}:=\frac{A+m c_{N}-a}{2(m+1)\left(p_{F}+t \eta\right)},
$$

such that,

$$
\frac{d E}{d \theta}\left\{\begin{array}{l}
>0 \text { if } 0<\theta<\hat{\theta} \\
=0 \text { if } \theta=\hat{\theta} \\
<0 \text { if } \hat{\theta}<\theta<\bar{\theta}
\end{array}\right.
$$

Note that a lower $\theta$ corresponds to more efficient power plant. The above equation indicates that an improvement in generation efficiency increases total emission of the industry if the fuel efficiency is lower than a threshold, ${ }^{7}$ and vice versa.

Concerning a combination with carbon tax, a higher tax level increases the threshold of generation efficiency. In other words, a higher tax level reduces $\hat{\theta}$; $d \hat{\theta} / d t<0$. This is because in a market where carbon tax is implemented, the direct effect of higher efficiency gets smaller with a reduction in the output of fossil-fuel power producers by the tax, which is represented by the first term in the bracket of Eq. (13), while the impact of the indirect effect, which is represented by the second term in the bracket of Eq. (13), increases with the rise in the carbon tax. Consequently, the required level of generation efficiency which enables total emission reduction goes up with an increase in the tax level. This means that the situation in which generation efficiency leads total emission expansion is more likely to occur as

\footnotetext{
5It can be interpreted as a form of the 'rebound effect'. In Sorrel (2009), the 'rebound effect' is described as "an umbrella term for a variety of mechanisms that reduce the potential energy savings from improved energy efficiency."

${ }^{6}$ Note that $\hat{\theta}=\bar{\theta} / 2$.

${ }^{7}$ It can be seen as a kind of 'Jevons' Paradox' suggested by William Stanly Jevons in 1865, that claims an improvement in energy efficiency will increase the overall energy consumption (Alcott 2005; Sorrel 2009). That is not the case under the cap and trade policy scheme in which the total emission is controlled by the cap that is set by the government. Under the cap and trade scheme, the gains in fuel efficiency does not affect the total emission. Instead, it would increase the price for the allowances by raising the marginal abatement costs of the fossil-fuel power producers.
} 
environmental tax increases. Similarly, a higher fuel price raises the threshold efficiency level. The fossil-fuel power producers reduce their outputs with an increase in fuel price. This diminishes the relative impact of the direct effect relative to the indirect effect. As a result, the required level of generation efficiency gets higher.

\subsection{Effect of Carbon Tax}

Next, I will be examining the effect of carbon tax. Differentiate Eqs. (7)-(9) with respect to $t$ yeilds,

$$
\begin{gathered}
\frac{d y}{d t}=-\frac{(m+1) \theta \eta}{(n+m+1) B}<0, \\
\frac{d x}{d t}=\frac{n \theta \eta}{(n+m+1) B}>0, \\
\frac{d Q}{d t}=-\frac{n \theta \eta}{(n+m+1) B}<0 .
\end{gathered}
$$

The above equations suggest that a reduction in carbon emission by the carbon tax leads a reduction in the total output $Q$, with a production shift from fossil-fuel power producers $y$ to the renewable power producers $x$.

The effect on the total emission is given by,

$$
\frac{d E}{d t}=-\frac{(m+1) n(\theta \eta)^{2}}{(n+m+1) B}<0 .
$$

In order to reduce a certain amount of emission $\Delta E,{ }^{8}$ the level of tax must be,

$$
t(\Delta E ; \theta)=t_{0}+\frac{(n+m+1) B}{(m+1) n(\theta \eta)^{2}} \Delta E,
$$

where $t_{0}$ denotes the initial tax level. ${ }^{9}$ We can see from the above equation that a gain in fuel efficiency (a reduction in $\theta$ ) raises the required tax level to reduce the equivalent amount of total emission;

\footnotetext{
${ }^{8}$ Suppose that $\Delta E$ corresponds to a reduction target set by the government. The analysis of this section focuses on the cost efficiency in achieving a certain level of reduction target. The major factor relevant to the cost efficiency would be the effect on consumer price and the external cost of $\mathrm{CO}_{2}$ emissions are offset each other when compared with the other level of the reduction target.

${ }^{9} \Delta E$ can be represented as,

$\Delta E=\int_{t_{0}}^{t_{1}} \frac{d E}{d t} d t$

where $t_{1}=t(\Delta E ; \theta)$.
} 


$$
-\frac{\partial t(\Delta E ; \theta)}{\partial \theta}>0
$$

Additionally, if $\theta>\hat{\theta}$, a gain in fuel efficiency increases the overall emission. It leads to a counterintuitive implication. The tax level must be raised with an improvement in fuel efficiency to achieve the equivalent target of carbon reduction, especially when the fuel efficiency is lower than the threshold $(\theta>\hat{\theta})$.

We can examine the relationship between the carbon reduction and the total output as follows,

$$
\frac{d Q}{d E}=\frac{d Q / d t}{d E / d t}=\frac{1}{(m+1) \theta \eta} .
$$

The above equation indicates that a $1 \mathrm{~kg}$ reduction in $\mathrm{CO}_{2}$ emission involves $1 /(m+1) \theta \eta(\mathrm{kWh})$ decrease in the total output. The reduction rate rises with an improvement in generation efficiency (corresponds with an increase in $\theta$ ). A decrease of $\Delta E$ in total emission brings about the corresponding decline in the total output:

$$
\Delta Q(\Delta E ; \theta)=\frac{\Delta E}{(m+1) \theta \eta} .
$$

It results in a rise in the consumer price and a welfare loss derived from the decreased total consumption. The corresponding reduction in the benefit of the demand side electricity consumption can be calculated as follows, ${ }^{10}$

$$
\Delta W^{D}=\frac{\Delta E}{(m+1) \theta \eta}\left\{A-\frac{B}{2}\left(2 Q_{0}+\frac{\Delta E}{(m+1) \theta \eta}\right)\right\},
$$

where $Q_{0}$ is the initial level of total output which is represented as Eq. (9).

In the same way, we can derive the effect of carbon reduction on the output of fossil-fuel power producers from Eqs. (16) to (19),

$$
\frac{d(n y)}{d E}=\frac{d(n y) / d t}{d E / d t}=\frac{1}{\theta \eta} .
$$

We can easily see that with a fuel-efficient power plant, a unit reduction of $\mathrm{CO}_{2}$ involves a greater reduction in the electricity output. A decrease of $\Delta E$ in $\mathrm{CO}_{2}$ emission involves a reduction of $\Delta E / \theta \eta$ in the output of fossil-fuel power producers, which increases with an improvement in the fuel efficiency (a lower $\theta$ ).

\footnotetext{
${ }^{10}$ Note that the reduction in total benefit can be written as follows,

$\Delta W^{D}=-\int_{Q_{0}}^{Q_{1}} P(q) d q$,

where $Q_{1}=Q_{0}-\Delta E /(m+1) \theta \eta$.
} 
Finally, it is useful to investigate the impact of carbon tax on the profit of fossil fuel power producers, since it would be relevant to political feasibility of the tax. ${ }^{11}$ The impact of the carbon tax on the profit can be written as follows,

$$
\frac{d \pi_{F}}{d t}=\frac{\partial \pi_{F}}{\partial y} \frac{d y}{d t}+\frac{\partial \pi_{F}}{\partial t} .
$$

Since $\partial \pi_{F} / \partial y=0$ from Eq. (5), the above equation can be rewritten as follows,

$$
\frac{d \pi_{F}}{d t}=\frac{\partial \pi_{F}}{\partial t}=-\eta \theta y .
$$

In the similar way with the above discussion, we can write the impact of a carbon reduction as follows,

$$
\frac{d\left(n \pi_{F}\right)}{d E}=\frac{d\left(n \pi_{F}\right) / d t}{d E / d t}=\frac{(n+m+1) B}{(m+1) \eta \theta} y .
$$

Since $d y / d \theta>0$ from Eq. (10), and the denominator of Eq. (21) decreases with a reduction in $\theta$, we can easily see that the marginal profit loss derived from the carbon reduction increases with an improvement in fuel efficiency. That is,

$$
\frac{d}{d \theta}\left[\frac{d\left(n \pi_{F}\right)}{d E}\right]<0 .
$$

\subsection{Summary: Generation Efficiency and Carbon Tax}

Table 1 summarizes the main results of this section. Case 1 describes a notable situation where an improvement in generation efficiency leads the overall $\mathrm{CO}_{2}$ emission expansion (Statement (1)) and the increase in the potential profit loss of fossil-fuel power producers by the carbon tax (Statements 3 and 4). It would be the case in which the tax increase provokes a fierce opposition from the fossil-fuel power producers.

In Case 2 at Table 1, the efficiency gain would contribute to the overall $\mathrm{CO}_{2}$ reduction. A comparative advantage of promoting fuel-efficient power plants relative to the carbon tax is that an improvement in fuel efficiency possibly increases a total electricity output [Eq. (12)] while it reduces the overall $\mathrm{CO}_{2}$ emission; in other words, it could decouple a carbon reduction from a decrease in the total electricity output. On the other hand, a carbon reduction by the carbon tax involves a decrease

\footnotetext{
${ }^{11}$ Resistance from the producers or the consumers could become a significant obstacle to introducing environmental taxes. In the policy proposal on long-term growth strategy of Japan under the Paris agreement (issued at March 19, 2019), Japan Business Federation expressed their opposition to promoting carbon pricing such that carbon tax and emissions trading scheme.
} 
Table 1 Impact of improvement in fuel efficiency

\begin{tabular}{l|l}
\hline $\begin{array}{l}\text { Case 1: } \\
\theta>\hat{\theta} \text { (lower efficiency) }\end{array}$ & $\begin{array}{l}\text { Case 2: } \\
\theta<\hat{\theta} \text { (higher efficiency) }\end{array}$ \\
\hline $\begin{array}{l}\text { (1) The overall emission } \\
\text { increases. }\end{array}$ & $\begin{array}{l}\text { (2) The overall emission } \\
\text { decreases. } \\
\text { Equation (15) }\end{array}$ \\
Equation (15) & $\begin{array}{l}\text { (3) The marginal profit loss of the fossil-fuel power producers } \\
\text { by the tax increases. }\end{array}$ \\
Equation (24) \\
$\begin{array}{l}\text { (4) The required tax level to reduce a certain amount of } \mathrm{CO}_{2} \\
\text { emission increases. }\end{array}$ \\
Equation (20)
\end{tabular}

in the total electricity output. The notable point is that an efficiency standard (which corresponds to $\hat{\theta}$ in the model of this section) is necessary in order to achieve an effective $\mathrm{CO}_{2}$ reduction by the efficiency improvement. An incorrect estimation of the critical threshold or irrelevant setting of the standard could cause the adverse effect. In addition, statements (3) and (4) in Table 1 still valid in Case 2, which would make it difficult to complement the effect of carbon reduction with the carbon tax.

Taking these factors into consideration, the results of this section indicate that promoting generation efficiency of fossil-fuel power plants is not a reliable way to reduce overall $\mathrm{CO}_{2}$ emission relative to the carbon tax. In other words, it is not a substitute of the tax; rather it would increase the political difficulty of implementation of the carbon tax, which is more reliable measure to reduce the overall emissions.

\section{Feed-in Tariff and Carbon Tax}

In this section, I consider a policy that simultaneously use feed-in tariff and carbon tax. The combination of these policies is worthy to investigate since they could possibly complement each other; FIT policy may be financed by the revenue of carbon tax, and a reduction in electricity supply by the carbon tax may be lessen by supporting renewable power generations under FIT.

Under feed-in tariff, the price of electricity generated from renewable power producers is fixed at $P_{R}$ which is set by the government. A third party network operator is obliged to purchase the electricity from renewable power producers at this fixed price. Assuming a quadratic cost function, the profit of the renewable electricity producers is given by,

$$
\pi_{R}^{j}:=P_{R} x_{j}-\frac{1}{2} c_{R} x_{j}^{2}-a x_{j}-k_{R}, \quad j=1, \cdots, m .
$$

Differentiating the profit function of the renewable power producers with respect to $y_{i}$ yields the first order condition for profit maximization as follows, 


$$
P_{R}-a=c_{R} x_{j}, \quad j=1, \cdots, m .
$$

Solving the first order condition, we obtain the output;

$$
x_{j}=x=\frac{P_{R}-a}{c_{R}}, j=1, \cdots, m,
$$

where $P_{R}>a$ is assumed to secure positive outputs of renewable power producers. Accordingly, the total output of the renewable electricity producers $X$ can be obtained as follows,

$$
X\left(P_{R}\right)=m\left(\frac{P_{R}-a}{c_{R}}\right) .
$$

The profit of the fossil-fuel power producers is given by,

$$
\pi_{F}^{i}:=(P-a) y_{i}-\frac{1}{2} c_{F} y_{i}^{2}-t c_{e} y_{i}-k_{F}, \quad i=1, \cdots, n .
$$

where $c_{e}\left(\mathrm{~kg}-\mathrm{CO}_{2} / \mathrm{kWh}\right)$ represents the carbon intensity of the electricity output. They go into Cournot competition taking the outputs of the renewable power producers (and corresponding residual demand) as given; that is determined by the price for renewable electricity set by the government as Eq. (27). The first order condition of profit maximization is,

$$
(A-B Q-a)-B y_{i}-c_{F} y_{i}-c_{e} t=0, i=1, \cdots, n \text {. }
$$

Assuming the symmetry in the equilibrium $\left(y_{i}=y\right.$ for all $\left.i\right)$, the equilibrium output is obtained as follows,

$$
y\left(P_{R}, t\right)=\frac{c_{R}\left\{A-\left(a+c_{e} t\right)\right\}-B m\left(P_{R}-a\right)}{\left\{(n+1) B+c_{F}\right\} c_{R}} .
$$

The total output of the whole industry is,

$$
Q\left(P_{R}, t\right)=\frac{n c_{R}\left(A-a-c_{e} t\right)+B m\left(P_{R}-a\right)+c_{R} c_{F}}{\left\{(n+1) B+c_{F}\right\} c_{R}} .
$$

\subsection{Feed-in Tariff}

To examine the effect of feed-in tariff, partially differentiating Eqs. (26), (30) and (31) with respect to $P_{R}$ yields, 


$$
\begin{gathered}
\frac{\partial y}{\partial P_{R}}=\frac{-B m}{\left\{(n+1) B+c_{F}\right\} c_{R}}<0, \\
\frac{\partial x}{\partial P_{R}}=\frac{1}{c_{R}}>0, \\
\frac{\partial Q}{\partial P_{R}}=\frac{B m}{\left\{(n+1) B+c_{F}\right\} c_{R}}>0 .
\end{gathered}
$$

An increase in the feed-in tariff raises the marginal revenue of the renewable power producers. As a result, it increases their outputs. It also creates a production shift from the fossil-fuel power producers to the renewable power producers in the market. Consequently, it indirectly reduces the carbon emissions in the whole industry. In contrast with the carbon tax, a rise in the policy variable, i.e., feed-in tariff, leads to an increase in the total output of the industry and involves a reduction in consumer price. Consequently, a rise in the feed-in tariff would reduce the welfare loss generated from the market power in the oligopoly. ${ }^{12}$

The effect on total emission is written as follows,

$$
\frac{\partial E}{\partial P_{R}}=\frac{-n c_{e} B m}{\left\{(n+1) B+c_{F}\right\} c_{R}}<0 .
$$

where $E:=n c_{e} y$ denotes the total amount of $\mathrm{CO}_{2}$ emission. An increase in the fixed price creates a production shift from the fossil-fuel power producers to the renewable power producers. As a result, it creates an indirect effect of reducing the industry-wide carbon emissions.

A sharp difference between the feed-in tariff and the carbon tax is that the feedin tariff involves an increase in the total electricity output (which corresponds to a lower consumer price) when it indirectly reduces the output of the fossil-fuel power producers. The relationship between the effects of feed-in tariff on the carbon reduction and the total output is represented as follows,

$$
\frac{d Q}{d E}=\frac{\partial Q / \partial P_{R}}{\partial E / \partial P_{R}}=-\frac{1}{n c_{e}}<0 .
$$

We can see from the above equation that a $1 \mathrm{~kg}$ reduction in the carbon emission by the feed-in tariff involves a $1 / n c_{e}(\mathrm{kWh})$ increase in the total output. In contrast with the case of carbon tax, feed-in tariff is able to reduce the carbon emissions without decreasing the total output; rather it increases with a rise in the feed-in tariff.

\footnotetext{
${ }^{12}$ In an imperfectly competitive market, policy effects of correcting distortions caused by the market power play an influential role (Hibiki and Kurakawa 2013).
} 


\subsection{Carbon Tax}

The effect of carbon tax is straightforward. The partial derivatives of market outcomes with respect to $t$ is obtained as follows,

$$
\begin{gathered}
\frac{\partial y}{\partial t}=\frac{-c_{e}}{\left\{(n+1) B+c_{F}\right\} c_{R}}<0, \\
\frac{\partial x}{\partial t}=0, \\
\frac{\partial Q}{\partial t}=\frac{-n c_{e}}{\left\{(n+1) B+c_{F}\right\} c_{R}}<0 .
\end{gathered}
$$

When the carbon tax is implemented together with feed-in tariff, the outputs of renewable power producers are solely determined by the feed-in tariff and are not affected by the carbon tax. In other words, a change in the tax level does not create production shift caused by the strategic interrelationship in the market, because the marginal revenues of the renewable power producers are fixed by the feed-in tariff. It merely reduces the output of fossil-fuel power producers and consequently decreases the total output of the power sector. A reduction in $\mathrm{CO}_{2}$ emission by the carbon tax involves a decrease in the total output and a rise in the consumer price.

The effect on carbon reduction can be represented as,

$$
\frac{\partial E}{\partial t}=\frac{-n\left(c_{e}\right)^{2}}{\left\{(n+1) B+c_{F}\right\} c_{R}}<0 .
$$

The impact of carbon reduction by the tax on the total output can be written as follows,

$$
\frac{\partial Q}{\partial E}=\frac{\partial Q / \partial t}{\partial E / \partial t}=\frac{1}{c_{e}}>0 .
$$

This equation indicates that a $1 \mathrm{~kg}$ reduction in the carbon emission by the tax involves a $1 / c_{e}(\mathrm{kWh})$ reduction in the total output.

\subsection{Combination of Feed-in Tariff and Carbon Tax}

Combination of the feed-in tariff and the carbon tax enables a policymaker to choose a pair of the emission level and the total output from the feasible region which is illustrated in Fig. 1. The lines $L_{0}$ and $L_{1}$ correspond to the lower limit and the upper limit of the feed-in tariff respectively, which would be determined by multiple factors (e.g., the break-even point of the renewable power producers). The slope of these 


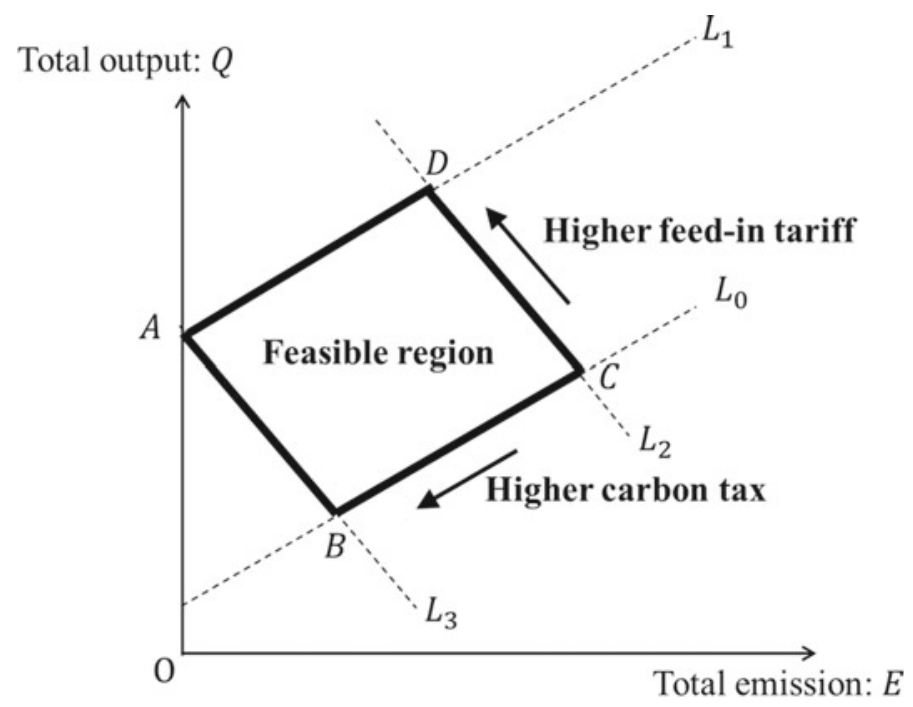

Fig. 1 The combined effect of the feed-in tariff and the carbon tax

lines is $1 / c_{e}$ as represented in Eq. (40). Similarly, the lines $L_{2}$ and $L_{3}$ respectively correspond to the lower limit and the upper limit of the carbon tax. The slope of $L_{2}$ and $L_{3}$ is $-1 / n c_{e}$ as Eq. (36) indicates.

As illustrated in Fig. 1, the carbon tax has a negative impact on the total output. When the carbon tax is implemented separately from the feed-in tariff, ${ }^{13}$ there is a trade-off between the carbon reduction and a fall in the total electricity output, that results in a rise in the consumer price. The feed-in tariff introduces a positive element of the total output, that greatly extend the range of possible choice for the policy maker. ${ }^{14}$ In other words, these policy instruments complement each other; the combination of these policies produce a potential welfare gain in the industry.

\section{Summary and Conclusion}

The analysis of Sect. 2 investigated the effects of generation efficiency gains in fossil fuel power plants (mainly supposing coal-fired power generation). It was shown that an improvement in generation efficiency of fossil-fuel power plants produced the following two effects:

\footnotetext{
${ }^{13}$ The possible range is segment $B C$ in Fig. 1 in this case.

${ }^{14}$ When the feed-in tariff is introduced separately from the carbon tax, the possible range is segment $C D$ in Fig. 1.
} 
1. The effect of reducing the fuel required to obtain the same amount of electricity

2. The effect of increasing the cost efficiency of the fossil-fuel power generation (reducing the marginal costs of fossil-fuel power producers), that gives them an advantage in competition relative to their rivals, the renewable power producers, and enables them to increase the market shares.

The latter effect (2) can be interpreted as a kind of the 'rebound effect', and the former can be referred as a 'saving effect'. The overall emission decreases if the 'saving effect' exceeds the 'rebound effect', and vice versa. The analysis in Sect. 2 demonstrated that

3. There exists a threshold level of fuel efficiency such that the 'conservation effect' exceeds the 'rebound effect' if the fuel efficiency is higher than the threshold. That is, the efficiency gains lead to a reduction in the total emission.

4. Conversely, if it is lower than the threshold, the "rebound effect" exceeds the "saving effect". That is, the efficiency gains lead to an increase in the total emission.

In order for an improvement in fuel efficiency to reduce total $\mathrm{CO}_{2}$ emission of the whole industry, it is necessary to achieve a certain level of technical standard. Efficiency gains in the lower levels will result in an increase in the total emission. In order to avoid such adverse effects, it is required that (1) accurately estimate the threshold level, (2) set the regulation level on the technical standard to an appropriate level that exceeds the threshold, and (3) clear the technical standard. If these conditions are not achieved, on the contrary, the total emission will increase. In addition, it was shown that the gains in the generation efficiency would increase political difficulty of introducing the carbon tax. Overall, these results indicate that improving generation efficiency of fossil-fuel power plants is not necessarily a reliable measure to reduce $\mathrm{CO}_{2}$ emissions.

In Sect. 3, I investigated the combination of FIT and carbon tax. It was demonstrated that FIT had the combined effect:

5. Supporting renewable power generations by FIT indirectly reduces $\mathrm{CO}_{2}$ emissions by causing production shifts from fossil-fuels power producers to the renewable power producers.

6. FIT has the effect of fostering competitive environment in which the consumer price falls with decreasing market power.

The effects (5) and (6), together with the possibility that FIT could be financed by revenue of carbon tax, indicate that combination of these policies produce potential welfare gain. 


\section{References}

Alcott B (2005) Jevons' paradox. Ecol Econ 54:9-21

Armstrong M, Cowan S, Vickers J (1994) Regulatory reform. MIT Press, Cambridge, Massachusetts, pp 148-159

Böhringer C, Rosendahl KE (2010) Green promotes the dirtiest: on the interaction between black and green quotas in energy markets. J Regul Econ 37:316-215

Hihiki A, Kurakawa Y (2013) Which is a better second best policy, the feed-in tariff scheme or the renewable portfolio standard scheme? Research Institute of Economy, Trade and Industry, Discussion paper 13-J-070, 2013 (written in Japanese)

Sorrel S (2009) Jevons' Paradox revisited: The evidence for backfire from improved energy efficiency. Energy Policy 37:1456-1469

Tamás MM, Shrestha SOB, Zhou H (2010) Feed-in tariff and tradable green certificate in oligopoly. Energy Policy 38:4040-4047

Yukihide Kurakawa is a tenured lecturer of Faculty of Economics at Kanazawa Seiryo University in Japan. He obtained Ph.D. from Tokyo Institute of Technology. He manly conducts microeconomic analyses on policy issues concerning environmental and energy problems. His recent research focuses on effective and efficient policy measures to promote renewable energy sources (RESs), as well as emerging problems arising from increasing shares of RESs.

Open Access This chapter is licensed under the terms of the Creative Commons Attribution 4.0 International License (http://creativecommons.org/licenses/by/4.0/), which permits use, sharing, adaptation, distribution and reproduction in any medium or format, as long as you give appropriate credit to the original author(s) and the source, provide a link to the Creative Commons license and indicate if changes were made.

The images or other third party material in this chapter are included in the chapter's Creative Commons license, unless indicated otherwise in a credit line to the material. If material is not included in the chapter's Creative Commons license and your intended use is not permitted by statutory regulation or exceeds the permitted use, you will need to obtain permission directly from the copyright holder.

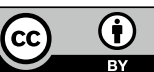

